\title{
Variation in Creeping Bentgrass Cultivar Responses to Drought Stress
}

\section{Sanalkumar Krishnan ${ }^{1}$ and Emily Merewitz ${ }^{1}$}

ADDITIONAL INDEX WORDS. drought resistance, photochemical yield, relative water content, turf quality, turfgrass

Summary. Creeping bentgrass (Agrostis stolonifera) is a desirable turfgrass putting green species that is susceptible to drought stress. Planting drought-resistant creeping bentgrass will enhance the resilience of golf turf surfaces, lower required resource inputs, and reduce the environmental impact of golf courses. Creeping bentgrass cultivar performance data during drought stress are needed for informed selection of appropriate cultivars. We evaluated the drought performance of 19 cultivars of creeping bentgrass and found that newer creeping bentgrass cultivars such as Pure Distinction and others exhibited superior drought performance compared with older cultivars such as Penncross and L93 based on turf quality, photochemical yield, and leaf relative water content. The results of this work should be used to aid in the selection of drought-resistant creeping bentgrass cultivars for turfgrass practitioners.

$\mathrm{T}$ The use of drought-tolerant plants can reduce water consumption in the turfgrass industry (Fry and Huang, 2004). Breeding of creeping bentgrass (Agrostis stolonifera), a golf course putting green species, has focused on biotic disease resistance, but has not focused much on abiotic stresses of creeping bentgrass such as drought stress (Meyer et al., 2017). Creeping bentgrass cultivars are synthetic because the species is highly outcrossingmeaning, there can be genetic variation within seeded cultivars (Warnke, 2003). Elite cultivars have been released, such as those bred for resistance to fungal diseases such as dollar spot [Clarireedia jacksonii, formerly known as Sclerotinia homeocarpa (Bonos, 2006)]. Scant information exists on the drought resistance of newer creeping bentgrass cultivars, and investigations of older cultivars

Received for publication 21 Sept. 2021. Accepted for publication 18 Nov. 2021.

Published online 1 February 2022

${ }^{1}$ Plant, Soil, and Microbial Sciences, Michigan State University, 1066 Bogue Street, East Lansing MI 48824

We thank Michigan State University AgBioRe search, Project GREEEN, and the Michigan Turfgrass Foundation for funding this work. We also thank Leah Brilman of Seed Research of Oregon for suppling seed from some of the cultivars.

Current address for S.K.: Smithers Oasis, Department of Grower \& Post-harvest R\&D, 295 S. Water Street, Kent, OH 44240

E.M. is the corresponding author. E-mail: merewitz@ msu.edu.

This is an open access article distributed under the CC BY-NC-ND license (https://creativecommons. org/licenses/by-nc-nd/4.0/).

https://doi.org/10.21273/HORTTECH04957-21 such as Penncross and L93 have been mechanistic (McCann and Huang, 2008; Salaiz et al., 1991). The National Turfgrass Evaluation Program (2021) has data on drought stress of some turfgrass species such as kentucky bluegrass (Poa pratensis), but has limited data on creeping bentgrass during drought stress. Important traits determined during genomic evaluation of creeping bentgrass breeding populations have not been evaluated further (Merewitz et al., 2012, 2014).

Surveys indicate that users of public turfgrass cultivar trials desire abiotic stress tolerance data, and cite abiotic stress resistance as being of primary importance to turfgrass professionals (Yue et al., 2017, 2019). This study aims to inform turfgrass scientists and practitioners on the drought performance of various creeping bentgrass cultivars by assessing drought tolerance in a controlled environment. We hypothesized that newer cultivars may have greater drought resistance compared with older cultivars as a result of years of selective breeding for other resilience traits.

\section{Materials and methods}

EXPERIMENTAL TREATMENTS. The 19 cultivars selected for this study included both older, more recently released cultivars and experimental genotypes. These cultivars and corresponding release dates (when available) were 007 (2006), 13M, IRH93, ISLTZ, Alpha (2004), Crenshaw (1993), Declaration (2005), L93 (1995), Mackenzie (2006), Mariner (1998), PennAl (1995), Penncross (1954), Pure Distinction (2013), Pure Selection (2013), Seaside2 (1967), Flagstick (2015), Tl (2004), Tyee (2006), and V8 (2001). Turfgrass plugs were taken using a cup cutter (diameter, 4 inches) from field plots $(5 \times 7 \mathrm{ft}$, seeded in 2014) at the Hancock Turfgrass Research Center, East Lansing, MI. The plugs were transferred to polyvinylchloride tubes (diameter, 4 inches; length, $40 \mathrm{~cm}$ ) filled with soil ( $70 \%$ sand, $30 \%$ loamy), established in a greenhouse for 2 weeks, and transferred to a growth chamber.

In the growth chamber (12-h photoperiod at $900 \mu \mathrm{mol} \cdot \mathrm{m}^{-2} \cdot \mathrm{s}^{-1}$ of photosynthetically active radiation, $65 \%$ relative humidity, and a day/night temperature of $23 / 20^{\circ} \mathrm{C}$ ), all plants were equally maintained, and fertilized weekly with half-strength nutrient solution (Hoagland and Arnon, 1950) until the drought treatment began. All plants started at the same moisture level and were trimmed to a l-inch canopy height. Water treatments included 1) control (wellwatered) and 2) water completely withheld (drought). The experiments were performed in Fall 2015 (OctoberNovember) and repeated in Spring 2016 (February-March). The water treatments commenced on 25 Oct. 2015 and concluded on 6 Nov. 2015; for 2016, the water treatments commenced on 28 Feb. and ended on 11 Mar. (total of $12 \mathrm{~d}$ of treatment for each experiment).

Measurements. Soil volumetric water content (SWC) was monitored daily throughout the studies in both years using a soil moisture meter (TDR 100; Spectrum Technologies, Aurora, IL) to a depth of $20 \mathrm{~cm}$. The evapotranspiration rate was measured via volumetric water loss from each pot using the gravimetric mass balance method

\begin{tabular}{llll}
\hline $\begin{array}{l}\text { Units } \\
\text { To convert U.S. to SI, } \\
\text { multiply by }\end{array}$ & U.S. unit & SI unit & $\begin{array}{l}\text { To convert SI to U.S., } \\
\text { multiply by }\end{array}$ \\
\hline 0.3048 & $\mathrm{ft}$ & $\mathrm{m}$ & 3.2808 \\
2.54 & inch $(\mathrm{es})$ & $\mathrm{cm}$ & 0.3937 \\
$\left({ }^{\circ} \mathrm{F}-32\right) \div 1.8$ & ${ }^{\circ} \mathrm{F}$ & ${ }^{\circ} \mathrm{C}$ & $\left({ }^{\circ} \mathrm{C} \times 1.8\right)+32$ \\
$\left({ }^{\circ} \mathrm{F} \div 1.8\right)+255.37$ & ${ }^{\circ} \mathrm{F}$ & $\mathrm{K}$ & $(\mathrm{K}-255.37) \times 1.8$
\end{tabular}

Horllechnology • April $202232(2)$ 

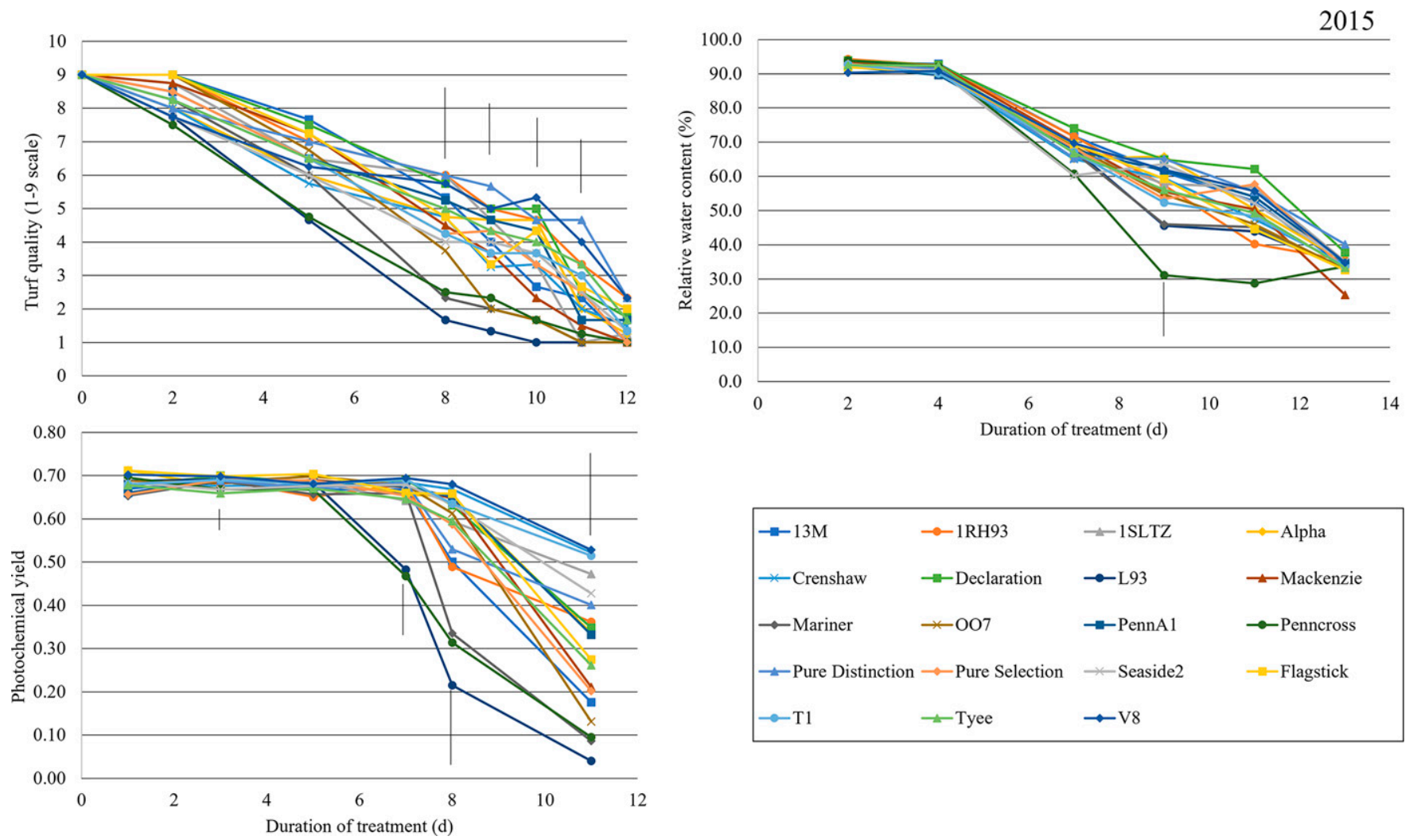

Fig. 1. Responses of creeping bentgrass turf quality, photochemical yield, and relative water content of different cultivars exposed to a complete withholding of water for drought stress under controlled growth chamber conditions in 2015 . Turf quality is rated on a scale of 1 to 9 , with $1=$ necrotic turf canopy and $9=$ healthy, green, and dense canopy. Differences among cultivar means were detected based on Fisher's protected least significant difference (LSD) test $(P \leq 0.05)$. Bars indicate LSD values.

(Young et al., 1997). Leaf relative water content (RWC) was determined on leaf samples (Barrs and Weatherley, 1962). Turf quality (TQ) was evaluated with a visual score that ranged from $\mathrm{l}$ to 9 , where $\mathrm{l}=$ brown, necrotic plants and $9=$ dense, green, and healthy grass (Beard, 2001). Photochemical yield $\left(\mathrm{Y}_{\mathrm{II}}\right)$, or quantum yield of photochemical energy conversion in photosystem II, was determined with a fluorometer (OSp5; Opti-Sciences, Hudson, $\mathrm{NH}$ ).

Statistical analysis. A completely randomized block design with four replicates was used, with watering treatment as the main block and cultivars randomized within the water treatment blocks. Effects of water and cultivar drought response were analyzed over time using analysis of variance based on the general linear model procedure of SAS (version 9.4; SAS Institute, Cary, NC). Results are presented separately by year because of differences in sampling date in each year. Fisher's protected least significant difference test at the $0.05 P$ level was used to detect differences between treatment means.

\section{Results and discussion}

SWC was not different among cultivars for either year or for wellwatered plants over time, but did decrease over time in the droughtstressed plants $(P \leq 0.05)$. Averaged across drought-treated cultivars in 2015, the SWCs were 28.5, 13.6, 6.9, and 2.1 for days $1,3,7$, and 11 of drought treatment, respectively. For 2016, the average SWCs were 22.1, $9.4,5.1$, and 2.7 for $1,5,8$, and $10 \mathrm{~d}$ of drought treatment, respectively. No differences were detected for water loss per day among cultivars in 2016 for evapotranspiration (data not shown). TQ was less for 'L93', 'Penncross', and 'Mariner' compared with other cultivars on days 8 through 11 of drought treatment in 2015 (Fig. 1), and the lower ranking cultivars in 2016 were L93, Penncross, and Tyee (Fig. 2). The highest-ranking cultivars for TQ in 2015 were Pure Distinction, V8, Declaration, and 1RH93; in 2016, they were Pure
Distinction, Flagstick, Pure Selection, and Declaration. RWC and $\mathrm{Y}_{\text {II }}$ observations are consistent with the rankings based on TQ. For instance, in 2016, $\mathrm{Y}_{\text {II }}$ was $\approx 62 \%$ greater for 'Pure Distinction' and 'Flagstick' compared with 'Penncross' and 'L93' after $8 \mathrm{~d}$ of drought. RWC for 'Pure Distinction' and 'Flagstick' was $44 \%$ and $22 \%$ greater, respectively, compared with 'Penncross' after $9 \mathrm{~d}$ of stress.

Differences among cultivars in RWC, $\mathrm{Y}_{\mathrm{II}}$, and TQ indicate that these parameters can indicate variation in creeping bentgrass drought responses. The results aid in the selection of drought-resistant creeping bentgrass cultivars for turfgrass practitioners. Future work should investigate these parameters in other turfgrass species and should validate these results under field conditions because conditions could be different from those in our study. Other work could include the evaluation of cultivars in a high-throughput manner, under restricted irrigation regimes, or in other environments. 

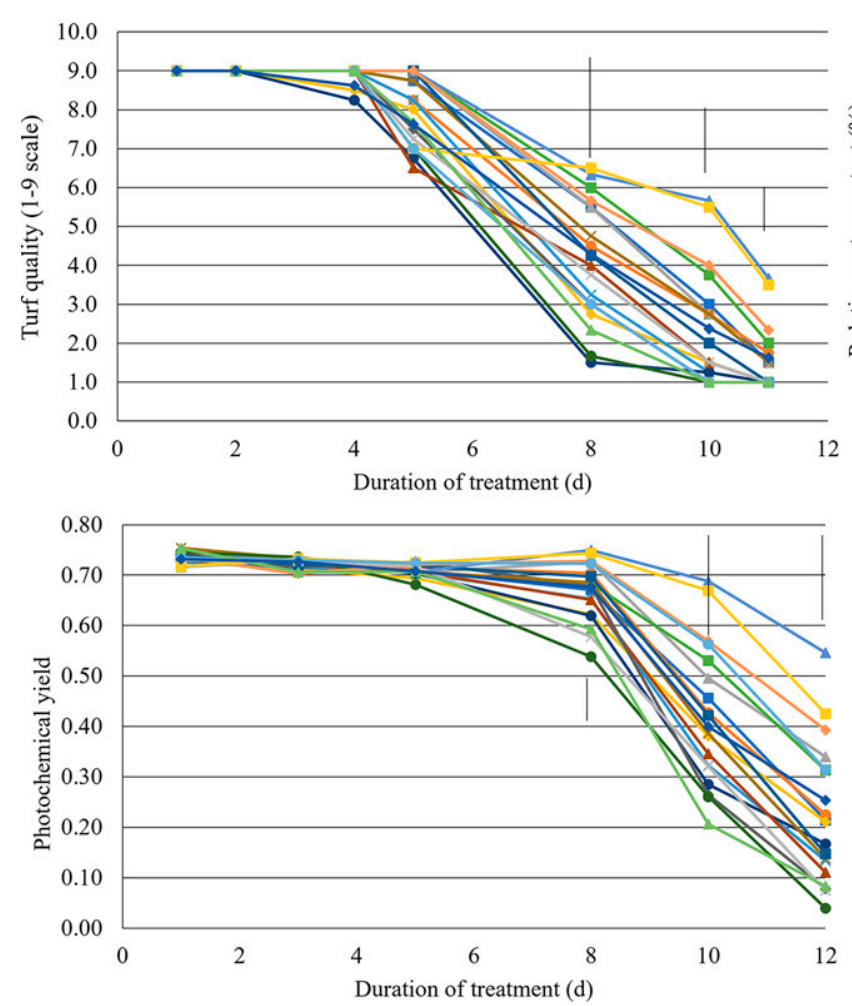

2016

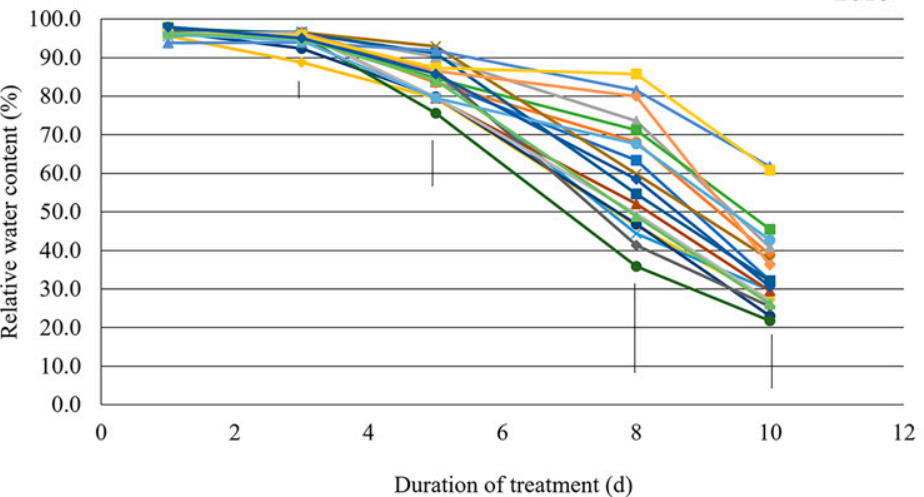

\begin{tabular}{llll}
$\rightarrow-13 \mathrm{M}$ & $\rightarrow-1$ RH93 & $\rightarrow$ - SLTZ & $\rightarrow$ Alpha \\
$\rightarrow$ Crenshaw & $\rightarrow-$ Declaration & $\rightarrow$ L93 & $\rightarrow$ Mackenzie \\
$\rightarrow-$ Mariner & $\rightarrow$ OO7 & $\rightarrow-$ PennA1 & $\rightarrow$-Penncross \\
$\rightarrow$ Pure Distinction & $\rightarrow$ Pure Selection & $\rightarrow$-Seaside2 & $\rightarrow$-Flagstick \\
$\rightarrow-$ T1 & $\rightarrow$ Tyee & $\rightarrow-$ V8 & \\
\hline
\end{tabular}

Fig. 2. Responses of creeping bentgrass turf quality, photochemical yield, and relative water content of different cultivars exposed to a complete withholding of water for drought stress under controlled growth chamber conditions in 2016 . Turf quality is rated on a scale of 1 to 9 , with $1=$ necrotic turf canopy and $9=$ healthy, green, and dense canopy. Differences among cultivar means were detected based on Fisher's protected least significant difference (LSD) test $(P \leq 0.05)$. Bars indicate LSD values.

\section{Literature cited}

Barrs, H.D. and P.E. Weatherley. 1962. A re-examination of the relative turgidity techniques for estimating water deficits in leaves. Aust. J. Biol. Sci. 15:413-428.

Beard, J.B. 2001. Turf management for golf courses. Ann Arbor Press, Chelsea, MI.

Bonos, S.A. 2006. Heritability of dollar spot resistance in creeping bentgrass. Phytopathology 96:808-812, https://doi. org/10.1094/PHYTO-96-0808.

Fry, J.D. and B. Huang. 2004. Applied turfgrass science and physiology. Wiley, Hoboken, NJ.

Hoagland, D.R. and D.I. Arnon. 1950. The water-culture method for growing plants without soil. University of California, College of Agriculture, Agricultural Experiment Station, Berkeley, CA.

McCann, S. and B. Huang. 2008. Evaluation of drought tolerance and avoidance traits for six creeping bentgrass cultivars. HortScience 43:519-524, https://doi. org/10.21273/HORTSCI.43.2.519.
Merewitz, E., F.C. Belanger, S.E. Warnke, and B. Huang. 2012. Identification of quantitative trait loci (QTL) that influence drought tolerance in a colonial $x$ creeping bentgrass hybrid population. Crop Sci. 52:1-11, https://doi.org/ $10.2135 /$ cropsci2012.01.0037.

Merewitz, E., F. Belanger, S. Warnke, B. Huang, and S. Bonos. 2014. Quantitative trait loci associated with drought tolerance in creeping bentgrass (Agrostis stolonifera L.). Crop Sci. 54:2314-2324, https:// doi.org/10.2135/cropsci2013.12.0810.

Meyer, W.A., L. Hoffman, and S.A. Bonos. 2017. Breeding cool-season turfgrass cultivars for stress tolerance and sustainability in a changing environment. Intl. Turfgrass Soc. Res. J. 13:3-10, https:// doi.org/10.2134/itsrj2016.09.0806.

National Turfgrass Evaluation Program. 2021. National Turfgrass Evaluation Program. 14 Oct. 2021. < http://www.ntep.org/>.

Salaiz, T.A., R.C. Shearman, T.P. Riordan, and E.J. Kinbacher. 1991. Creeping bentgrass cultivar water use and rooting responses. Crop Sci. 31:1331-1334, https://doi.org/10.2135/cropscil991. 0011183 X003100050050x.
Warnke, S. 2003. Creeping bentgrass (Agrostis stolonifera L.), p. 175-185. In: M.D. Casler and R.R. Duncan (eds.). Turfgrass biology, genetics, and breeding. Wiley, Hoboken, NJ.

Young, M.H., P.J. Wierenga, and C.F. Mancino. 1997. Monitoring near-surface soil water storage in turfgrass using time domain reflectometry and weighing lysimetry. Soil Sci. Soc. Amer. J. 61:1138-1146, https://doi.org/ $10.2136 /$ sssaj1997.036159950061000 $40021 \mathrm{x}$.

Yue, C., J. Wang, E. Watkins, S.A. Bonos, K.C. Nelson, J.A. Murphy, W.A Meyer, and B.P. Horgan. 2017. An investigation of trait prioritization in turfgrass breeding programs. HortScience 52 : 1544-1549, https://doi.org/10.21273/ HORTSCI12027-17.

Yue, C., J. Wang, E. Watkins, Y. Xie, S. Shekhar, S.A. Bonos, A. Patton, K. Morris, and K. Moncada. 2019. User preferences of accessing publicly available turfgrass cultivar performance data: an investigation of trait prioritization in turfgrass breeding programs. HortTechnology 52:1544-1549, https://doi.org/10.21273/ HORTTECH04390-19lofl2. 